\title{
Metal-Assisted Hydrolysis Reactions Involving Lipids: A Review
}

\author{
Dominique E. Williams ${ }^{1}$ and Kathryn B. Grant ${ }^{2 *}$ \\ ${ }^{1}$ Department of Chemistry, University of Richmond, Richmond, VA, United States, ${ }^{2}$ Department of Chemistry, Georgia State \\ University, Atlanta, GA, United States
}

This report covers major advances in the use of metal ions and complexes to hydrolyze ester and phosphate ester lipid bonds. These metal-based Lewis acids have been investigated as catalysts to isolate fatty acids from biological sources, as probes to study phospholipid bilayer properties, as tools to examine signal transduction pathways, and as lead compounds toward the discovery of therapeutic agents. Metal ions that accelerate phosphate ester hydrolysis under mild conditions of temperature and $\mathrm{pH}$ may have the potential to mimic phospholipase activity in biochemical applications.

Keywords: cleavage, fatty acids, liposomes, phospholipase mimics, triglycerides

\section{OPEN ACCESS}

Edited by:

Rajeev Prabhakar.

University of Miami, United States

Reviewed by:

Sanjay Singh,

Ahmedabad University, India

Salah S. Massoud,

University of Louisiana at Lafayette,

United States

Alfredo M. Angeles-Boza,

University of Connecticut,

United States

*Correspondence:

Kathryn B. Grant

kbgrant@gsu.edu

Specialty section: This article was submitted to

Inorganic Chemistry,

a section of the journal

Frontiers in Chemistry

Received: 28 September 2018 Accepted: 08 January 2019

Published: 19 February 2019

Citation:

Williams DE and Grant KB (2019) Metal-Assisted Hydrolysis Reactions

Involving Lipids: A Review.

Front. Chem. 7:14

doi: 10.3389/fchem.2019.00014

\section{INTRODUCTION}

Metal ions and complexes that hydrolyze biological molecules have become increasingly important to the fields of chemistry and biology (Grant and Kassai, 2006; Mancin et al., 2012, 2016; Wezynfeld et al., 2016; Yu et al., 2016). The majority of the studies in this area have focused on the reversible addition of water across ribo- and deoxyribonucleic acid phosphodiester bonds and peptide and protein amide bonds. Hydrolytically active metal ion centers such as $\mathrm{Ce}(\mathrm{IV}), \mathrm{Co}(\mathrm{II}), \mathrm{Co}(\mathrm{III}), \mathrm{Cu}(\mathrm{II})$, $\mathrm{Fe}(\mathrm{III}), \mathrm{Ln}(\mathrm{III}), \mathrm{Ni}(\mathrm{II}), \mathrm{Mo}(\mathrm{IV}), \mathrm{Pd}(\mathrm{II}), \mathrm{Zn}(\mathrm{II})$, and $\mathrm{Zr}(\mathrm{IV})$ have been considered for a number of diverse applications, e.g., as probes to study protein function and solution structure, as enzyme models that examine metallo-hydrolase activity, and as hydrolytic agents in nucleic acid and protein engineering experiments. Although metal-assisted hydrolysis of lipids remains relatively unexplored, it is undoubtedly of equal importance. Lipids play central roles in biological systems as energy-storage molecules and as chemical messengers in cell signaling (Wenk, 2010). As the major components of the biological membranes that surround all cells and organelles, phospholipids are of particular significance to almost all known life forms (Figure 1A).

\section{ISOLATION AND RECYCLING OF FATTY ACIDS FROM BIOLOGICAL SOURCES}

Fatty acids (Figure 1B) are key building blocks of complex lipid molecules including phospholipids, triglycerides, and sterol esters. Lipids containing 2-hydroxy fatty acid units (Figure 1C) are found in wool wax, microorganisms, as well as in the animal central nervous system, skin, and kidney (Kishimoto and Radin, 1963). In phospholipid bilayers, the 2'-OH group of 2-hydroxy lipids forms hydrogen bonds that strengthen membrane structure (Hama, 2010).

In one of the earliest reports appearing on metal-assisted lipid hydrolysis, Wernette and co-workers isolated free 2-hydroxy fatty acids by using $\mathrm{Cu}\left(\mathrm{NO}_{3}\right)_{2}$ to hydrolyze 2-hydroxy fatty acid methyl esters $\left(50^{\circ} \mathrm{C}\right.$ in water or methanol-water, 3 to $6 \mathrm{~h}$ ) (Boyer et al., 1979). Methyl ester cleavage was proposed to occur via the formation of a bis complex containing a central copper(II) ion and two 2-hydroxy fatty acid ligands (Figure 1D). Interaction of the metal ion center of 


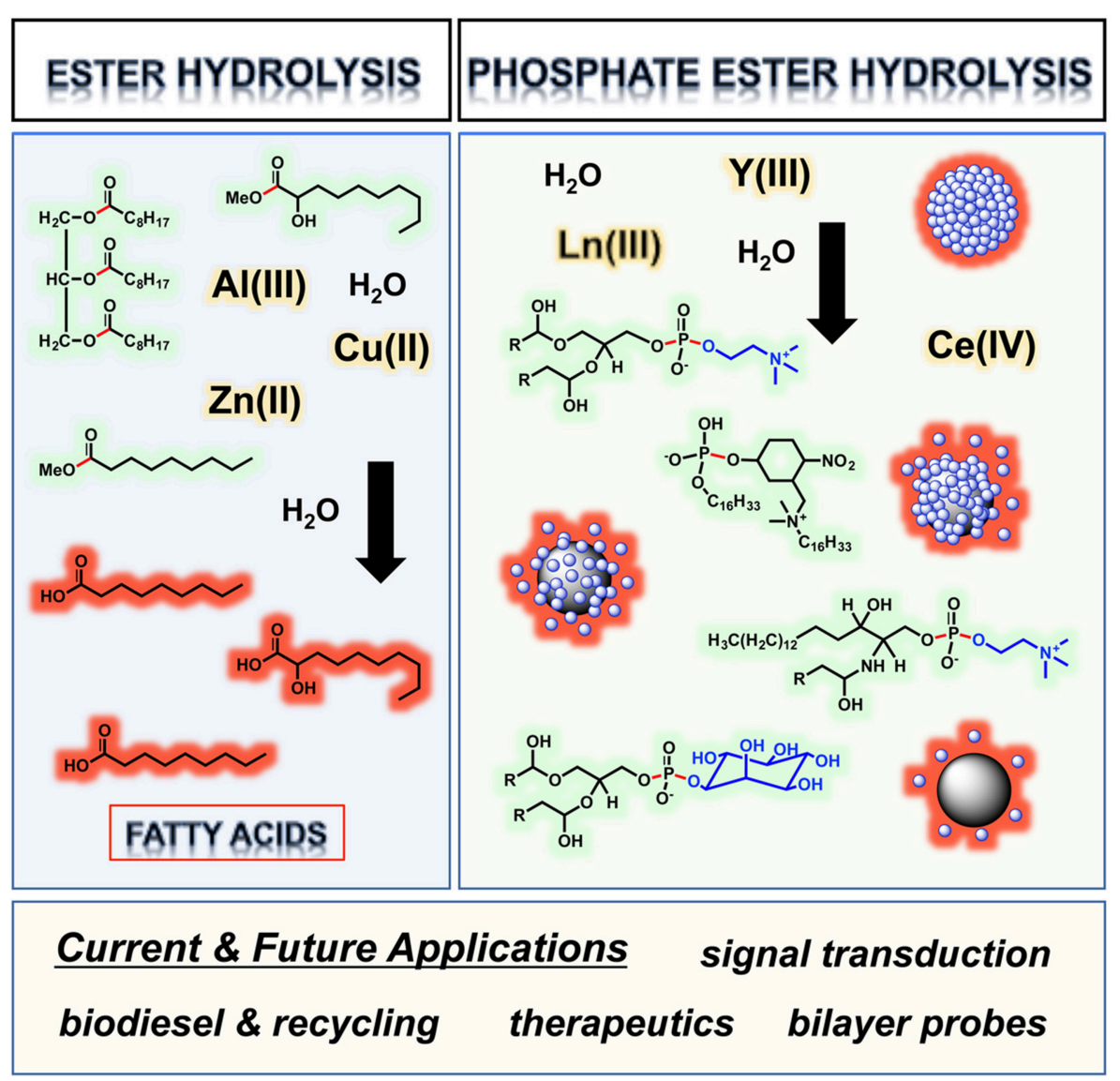

GRAPHICAL ABSTRACT | Metal ion centers hydrolyzing ester bonds in lipids and the phosphate ester bonds of phospholipid liposomes, with scissile linkages and polar head groups respectively highlighted in red and blue.

the complex with the methyl ester carbonyl oxygen atom of each fatty acid unit activated the corresponding carbonyl carbon toward nucleophilic attack by water (or hydroxide), leading to the production of two equiv. of methanol and a $\mathrm{Cu}(2$-hydroxy acid) $)_{2}$ precipitate. Subsequent EDTA treatment released the 2hydroxy fatty acid ligands in $80-82 \%$ yield (Entry 1 in Table S1, Supplementary Material). Wernette suggested that it should be possible to employ $\mathrm{Cu}(\mathrm{II})$ ions to hydrolyze complex lipids present in biological extracts, allowing for naturally occurring 2-hydroxy fatty acids to be isolated readily.

Free fatty acid building blocks have also been generated by using metal ions to hydrolyze triglycerides (Figure 1E). In addition to their importance as key components of biological lipids, fatty acids are of considerable commercial interest as a raw material in the manufacture of detergents, soaps, lubricants, plasticizers, and biodiesel, a fuel consisting of mono alkyl esters prepared using fatty acids from vegetable oil and animal fat (Knothe, 2010). Recycling of fatty acids from waste oils has led to important new, environmentally friendly processes for biodiesel production (Hajjari et al., 2017). Toward these ends, Ratnasamy et al. reacted the solid $\mathrm{Fe}(\mathrm{II})-\mathrm{Zn}$ (II) double-metal cyanine catalyst $\mathrm{K}_{4} \mathrm{Zn}_{4}\left[\mathrm{Fe}(\mathrm{CN})_{6}\right]_{3} \bullet \mathrm{H}_{2} \mathrm{O}(\mathrm{Fe}-\mathrm{Zn} \mathrm{DMC})$ with vegetable oils and animal fats in batch reactors (Satyarthi et al., 2011). DMC catalysts have zeolite-like cage structures and are traditionally used in the manufacture of polyether polyols (Almora-Barrios et al., 2015). Compared to the $14 \%$ hydrolysis yield obtained in the absence of catalyst, Ratnasamy et al. used Fe-Zn DMC to convert triglycerides in the starting material to free fatty acids with a yield of $72 \%$ and a turnover number of $25\left(190^{\circ} \mathrm{C}\right.$ in water, 8 h; Entry 2 in Table S1). Tetrahedrally coordinated Zn(II) Lewis acid centers within the catalyst were proposed to activate acyl ester bonds in the triglycerides toward nucleophilic attack by water.

As an innovative approach to biodiesel production, Ismadji et al. utilized synthetic $\mathrm{Cu}(\mathrm{II})$-laden wastewater to hydrolyze acylglycerides in waste cooking oil (Ong et al., 2016, 2017). The authors viewed the proposed method as a process that would not only furnish free fatty acid, but one that would remediate wastewater toxicity and conserve the large amounts of water consumed in traditional oil splitting. Using an aqueous solution of $\mathrm{CuSO}_{4}$ and waste cooking oil from a local restaurant, a total of $83.0 \%$ of the acylglycerides in the oil was hydrolyzed to fatty acids ( $77.6 \%$ yield, $225^{\circ} \mathrm{C}, 8 \mathrm{~h}$; Entry 3 in Table S1) (Ong et al., 2016). While these values were only slightly lower in reactions run with copper-free water (75.7\% acylglyceride conversion, $69.6 \%$ fatty acid yield), $51.8 \%$ of the copper(II) in the wastewater was 

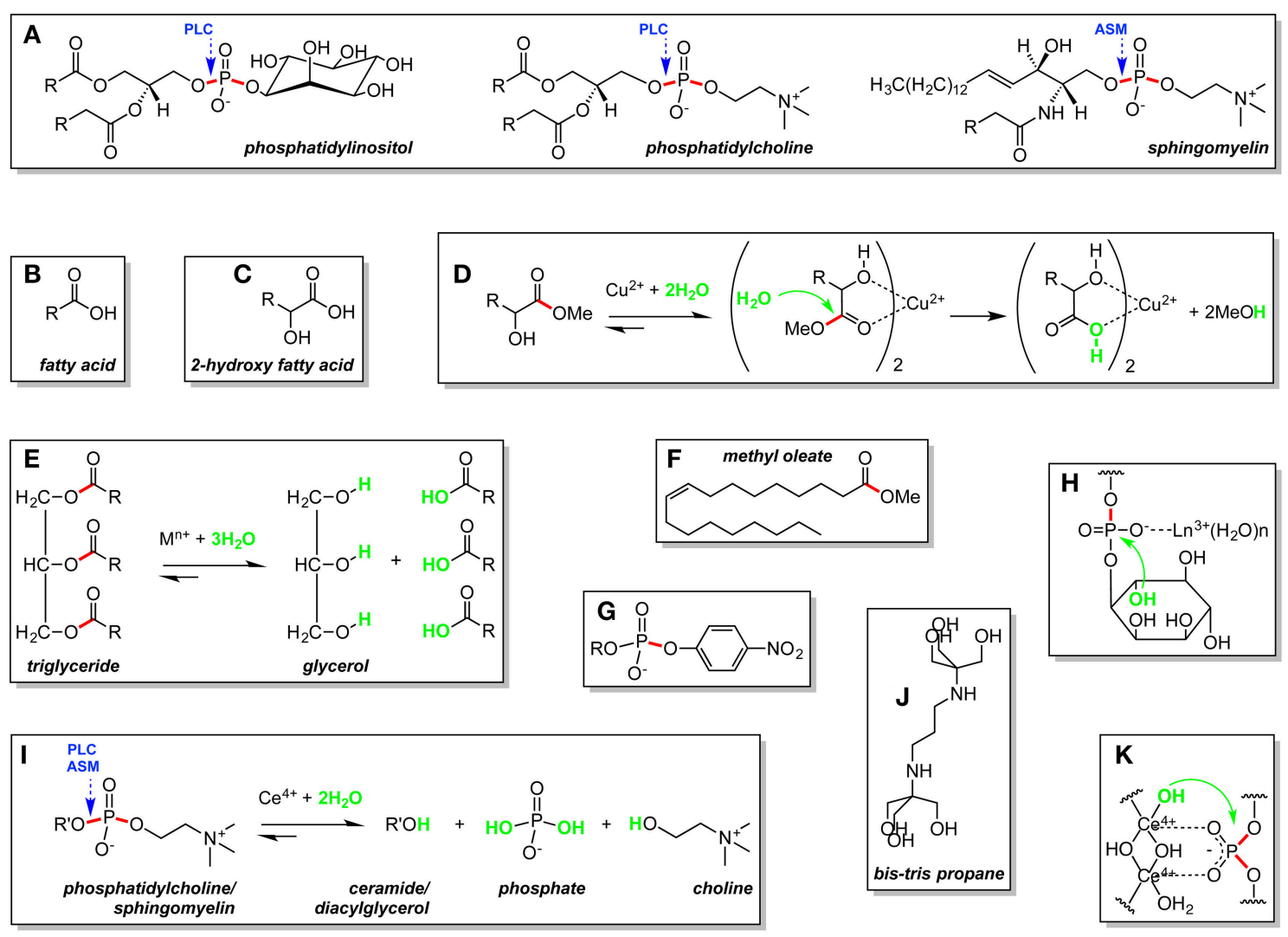

FIGURE 1 | Lipid (A-G) and ligand (J) structures, metal-assisted lipid hydrolysis reactions (D,E,I), and metal-assisted lipid hydrolysis mechanisms (D,H,K) described in the manuscript. R, hydrocarbon chain; R', diacylglycerol for phosphatidylcholine and ceramide for sphingomyelin; $M$, metal; $n+$, charge. Scissile ester bonds are in red. Nucleophiles are in green. Bond hydrolyzed by phospholipase $C(P L C)$ and acid sphingomyelinase (ASM) are identified with blue arrows.

successfully removed by the hydrolyzed oil phase of the reaction. Cumulative copper(II) detoxification was increased from 51.8 to $85.2 \%$ when the same sample of wastewater was utilized to treat a second batch of cooking oil (77.6\% acylglyceride conversion, $72.2 \%$ fatty acid yield).

While the global production and consumption of biodiesel have expanded, there are concerns that the oxygen atoms present in biodiesel lipids adversely affect stability, energy density, and other fuel properties (Knothe, 2010). Triglycerides from vegetable oils and animal fats have therefore been subjected to direct hydrodeoxygenation reactions to generate oxygen-free, hydrocarbon-based renewable (green) diesel fuels (Knothe, 2010). Coumans and Hensen recently studied the interactions between the heterogeneous sulfided green diesel catalyst $\mathrm{NiMo} / \gamma-\mathrm{Al}_{2} \mathrm{O}_{3}$ and the "model triglyceride" methyl oleate (Figure 1F) (Coumans and Hensen, 2017). The NiMo/ $\gamma$ $\mathrm{Al}_{2} \mathrm{O}_{3}$ catalyst was prepared by grinding and sieving a porous $\gamma$-alumina $\left(\gamma-\mathrm{Al}_{2} \mathrm{O}_{3}\right)$ solid support pre-treated with $\mathrm{Ni}\left(\mathrm{NO}_{3}\right)_{2} \bullet 6 \mathrm{H}_{2} \mathrm{O}$ and $\left(\mathrm{NH}_{4}\right)_{6} \mathrm{Mo}_{7} \mathrm{O}_{24} \bullet 7 \mathrm{H}_{2} \mathrm{O}$. Reactions between methyl oleate and the catalyst were conducted in a singlepass micro flow reactor under trickle flow conditions $\left(260^{\circ} \mathrm{C}\right.$ in tetralin, 60 bar, $\sim 2$ h; Entry 4 in Table S1). Near-complete conversion of methyl oleate to C17 and C18 hydrocarbons was observed. Based on the distribution of reaction intermediates and products, Coumans and Hensen proposed a reaction pathway in which hydrolysis of methyl oleate to fatty acid intermediates was catalyzed by coordinately unsaturated $\mathrm{Al}$ (III) centers of high Lewis acid strength located on the $\gamma$-alumina surface (Wischert et al., 2014). Direct hydrodeoxygenation of the fatty acids by the $\mathrm{Ni}(\mathrm{II}) / \mathrm{Mo}$ (VI) metal sulfide phase of the catalyst then gave rise to $\mathrm{C} 18$ hydrocarbons, while $\mathrm{H}_{2} \mathrm{~S}$-assisted decarbonylation (or decarboxylation) yielded C17 hydrocarbons.

\section{SYNTHETIC LIPID ANALOGS: ANALYSIS OF BILAYER PERMEABILITY AND DYNAMICS}

Metal ions and complexes that hydrolyze lipids under nondenaturing conditions of temperature and $\mathrm{pH}$ have been used to investigate the properties of phospholipid bilayers under physiological conditions (Mancin et al., 2016). In these studies, Moss et al. modeled bilayers by incorporating double-chain synthetic lipid analogs containing p-nitrophenol activated phosphate ester bonds into unilamellar liposomes (Figure 2). While $p$-nitrophenol is an excellent colorimetric tool, integrating this chromophore into a synthetic phospholipid (Figure 1G) increases the susceptibility of scissile bonds toward hydrolysis. 


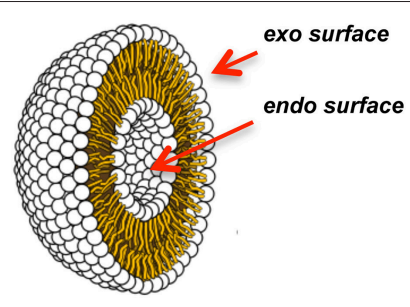

FIGURE 2 | Cross-section through a unilamellar liposome.

The liposomes were reacted under mild conditions upon the addition of the lanthanide metal ions $\mathrm{Eu}(\mathrm{III}), \mathrm{Lu}(\mathrm{III}), \mathrm{Tb}$ (III), $\mathrm{Tm}$ (III), and/or $\mathrm{Yb}(\mathrm{III})$ to the external bulk solution $\left(25-27^{\circ} \mathrm{C}\right.$ and $\mathrm{pH}$ 7.0-7.3; Entries 5 and 6 in Table S1) (Moss et al., 1995; Scrimin et al., 1998, 2000). Reactions were monitored via colorimetric detection of the $p$-nitrophenolate anion that was released upon metal-assisted hydrolysis (Figure S1). Relevant information relating to transverse lipid diffusion (flip-flop) rates was then revealed. At temperatures below the phase transition temperature $\left(T_{\mathrm{c}}\right)$ of the liposome, hydrolysis of the $p$-nitrophenol activated phosphate ester lipid bonds occurred only at the exoliposomal bilayer surface facing the bulk solution, independent of the charge, positive or negative, of the bilayer lipids (Figure 2). This confirmed that free ions are generally unable to permeate across biological membranes. Above the $T_{\mathrm{c}}$ however, rapid transverse diffusion of the synthetic lipids from the interior endo surface to the exo surface of the liposomes gave rise to additional metal-assisted cleavage. The hydrolytically active lanthanides were also used to manipulate bilayer properties. For example, Moss et al. showed that the permeability barrier of liposomes could be overcome by utilizing lipophilic amine ligands to coordinate to metal ions and then transport them by transverse diffusion from the outer to the inner membrane leaflet (Scrimin et al., 1998). When Ln(III) ions were employed to hydrolyze one of the two aliphatic chains of p-nitrophenol activated exo surface lipids (Figure S2), the rapid exposure of the endoliposomal surface to metal ions triggered an escalation in cleavage accompanied by the release of fluorescent reporter molecules stored within the liposomes' interior (Scrimin et al., 2000).

\section{METAL IONS AS PHOSPHOLIPASE MIMICS}

In addition to synthetically activated phosphate esters, lanthanide ions can hydrolyze unactivated phosphate ester bonds in naturally occurring phospholipids. As strong Lewis acids equipped with high charge densities, high coordination numbers, and rapid ligand exchange rates, the lanthanides are ideally suited as oxophilic, hydrolytic agents (Franklin, 2001). Consistent with the electrostatic nature of lanthanide-ligand interactions, these metal ion centers are drawn to negatively charged oxygen atoms in phospholipid phosphate ester bonds (Hauser and Phillips, 1976). When hydrolysis of unactivated phospholipids occurs at physiological temperature and $\mathrm{pH}$, the lanthanide ions have the potential to mimic phospholipase activity.
Phospholipases are enzymes that hydrolyze ester or phosphate ester bonds. They can be either cytoplasmic or lysosomal in origin. An important example of a cytoplasmic phospholipase is phosphatidylinositol-specific phospholipase C (PLC), which converts the phosphoglyceride phosphatidylinositol (PI; Figure 1A) to diacylglycerol and phosphorylated inositol, important secondary messengers in signal transduction (Figure S3) (Cocco et al., 2015). The lysosome is a cellular organelle that contains acid hydrolases that hydrolytically breakdown macromolecules into their original, monomeric building blocks (Appelqvist et al., 2013). Unlike cytoplasmic enzymes, acid hydrolase activity is typically optimal at lysosomal $\mathrm{pH}(\sim \mathrm{pH} 4.8)$ and significantly lower at cytoplasmic $\mathrm{pH}(\sim 7.2)$. Examples of acid hydrolases that engage in phosphate ester bond hydrolysis include: (i) acid sphingomyelinase (ASM) (Jenkins et al., 2009), which acts on the sphingolipid sphingomyelin (SM) to release ceramide and (ii) lysosomal phospholipase C (Matsuzawa and Hostetler, 1980), that hydrolyzes phosphoglycerides such as phosphatidylcholine (PC) and phosphatidylinositol to form diacylglycerol (Figure 1A).

\section{Cytoplasmic Phospholipase Mimics: Tools to Study Signal Transduction}

The first phospholipase mimics were discovered by the research groups of Komiyama and Liu, who used Ce(III), Eu(III), $\mathrm{La}(\mathrm{III}), \mathrm{Tb}(\mathrm{III}), \mathrm{Tm}(\mathrm{III})$, and $\mathrm{Y}(\mathrm{III})$ metal ion salts under nearphysiological conditions $\left(30-37^{\circ} \mathrm{C}, \mathrm{pH} 7.5-8.5\right.$; Entries 7 and 8 in Table S1) to hydrolyze naturally occurring, unactivated phosphatidylinositol (Figure 1A) in liposomes (Matsumura and Komiyama, 1994) and intact erythrocyte membranes (Liu et al., 2001). The rare earth ions "mimicked" the activity of cytoplasmic phosphatidylinositol-specific phospholipase C by converting the phosphatidylinositol to diacylglycerol and phosphorylated inositol (Figure S3). The two most active metal ions were $\mathrm{Y}$ (III) in PI liposomes ( $32 \%$ yield, $30^{\circ} \mathrm{C}$ and $\mathrm{pH} 8.0,24 \mathrm{~h}$ ) and $\mathrm{La}(\mathrm{III})$ in PI-laden erythrocyte membranes. In contrast, hydrolysis was not observed when PC liposomes were treated with Y(III). Komiyama thus proposed a hydrolytic mechanism in which a rare earth ion binds to a negatively charged phosphate oxygen atom of $\mathrm{PI}$, activating the phosphorous atom toward nucleophilic attack by the 2-hydroxy group specific to inositol (Figure 1H). The results of these investigations suggested that it should be possible to use hydrolytically active rare earth metal ions as "cytoplasmic phospholipase mimics" to study signal transduction pathways, e.g., via the generation of diacylglycerol and phosphorylated inositol in phospholipase deficient cell lines and animal models (Li et al., 2000).

\section{Mimicking Lysosomal Phospholipase: A Potential Therapeutic Application for Cerium(IV)}

Williams, Grant et al. have focused on phosphatidylcholine (Figure 1A) and sphingomyelin (Figure 1A) (Kassai et al., 2011; Cepeda et al., 2012), which make up approximately $50 \%$ of 
the phospholipid content of eukaryotic bilayer membranes. The authors utilized unactivated liposomes to model biological membranes and phosphate-specific colorimetric detection based on malachite green to quantitate hydrolysis. When PC and SM liposomes were treated with metal ion salts of $\mathrm{Ce}(\mathrm{IV})$, $\mathrm{Zr}(\mathrm{IV}), \mathrm{Hf}(\mathrm{IV}), \mathrm{Co}(\mathrm{II}), \mathrm{Cu}(\mathrm{II}), \mathrm{Eu}(\mathrm{III}), \mathrm{La}(\mathrm{III}), \mathrm{Ni}(\mathrm{II}), \mathrm{Pd}(\mathrm{II})$, $\mathrm{Y}(\mathrm{III}), \mathrm{Yb}(\mathrm{III})$, and $\mathrm{Zn}(\mathrm{II})$ at $60^{\circ} \mathrm{C}(20 \mathrm{~h})$, cerium(IV) displayed overwhelmingly superior levels of phosphodiester cleavage, releasing inorganic phosphate in appreciable yields at lysosomal pH ( 4.8; PC 41\%, SM 22\%) and in low yields under near neutral conditions ( $\sim \mathrm{pH}$ 7.2; PC 13\%, SM 5\%; Entries 9 and 10 in Table S1; Figure 1I). Two major factors where proposed to account for the preference of $\mathrm{Ce}(\mathrm{IV})$ for mildly acidic conditions. The $\mathrm{p} K_{\mathrm{a}}$ value of $\mathrm{Ce}(\mathrm{IV})$-bound water is approximately -1.1 (Wulfsberg, 1987), which enables this metal ion center to generate hydrolytically active hydroxide nucleophiles even at low $\mathrm{pH}$ values. Secondly, the multinuclear Ce(IV) hydroxo species responsible for phosphodiester hydrolysis lose positive charge and Lewis acid strength as reaction $\mathrm{pH}$ is raised (Maldonado and Yatsimirsky, 2005). Among the lanthanide(III) ions tested, liposomes were cleaved only at $\mathrm{pH} \mathrm{7.2,} \mathrm{albeit}$ in extremely low yields $<2 \%$. Unlike cerium(IV), water molecules bound to $\operatorname{Ln}(\mathrm{III})$ ions have $\mathrm{p} K_{\mathrm{a}}$ values that support phosphate ester bond hydrolysis under neutral to slightly alkaline conditions, e.g., $\sim 8.0$ for $\mathrm{Eu}(\mathrm{III}), \sim 8.0$ for $\mathrm{Yb}$ (III), and $\sim 8.5$ for $\mathrm{La}(\mathrm{III})$ (Burgess, 1978; Wulfsberg, 1987). The hydrolytic superiority of cerium is likely to be related to its +4 oxidation state (Bracken et al., 1997). In addition to increasing the acidity of metal-bound water, the elevated charge density of Ce(IV) intensifies its Lewis acid strength.

The high cerium(IV) activity at lysosomal $\mathrm{pH}$ coupled with the ability to hydrolyze SM and PC phosphate ester bonds on the ceramide/diacylglycerol side of phosphate suggest that this metal ion center might serve as an acid sphingomyelinase or lysosomal phospholipase C mimic (Figure 1I). In order for such an enzyme mimic to be optimal, cleavage should occur at physiological temperature and should be greatly diminished in neutral environments. To further enhance and tune cerium(IV) chemistry, Williams et al. turned to the chelating ligand bis-tris propane (BTP; Figure 1J) (Williams et al., 2015). Upon the addition of BTP to optimized $37^{\circ} \mathrm{C}$ reactions, cerium(IV) hydrolyzed unactivated $\mathrm{PC}$ liposomes to release 5.7 times more inorganic phosphate at $\sim \mathrm{pH} 4.8$ than at $\sim \mathrm{pH} 7.2$, a major enhancement compared to the $\sim 2.1$ fold increase that was observed in ligand free controls $(20 \mathrm{~h})$. In the presence of BTP, the yield of inorganic phosphate at $\mathrm{pH} 4.8$ and $37^{\circ} \mathrm{C}$ was $67 \%$, a value that is roughly equivalent to the percent of phospholipid molecules found on the metal-accessible exo surface of small liposomes (Entry 11 in Table S1). NMR studies indicated that the $\mathrm{pH}$-dependent "on-off switch" of the BTP ligand is related to the $\mathrm{p} K_{\mathrm{a}}$ values of its nitrogen donor atoms $\left(\mathrm{p} K_{\mathrm{a} 1}=6.8, \mathrm{p} K_{\mathrm{a} 2}=\right.$ 9.1) (Maldonado and Yatsimirsky, 2005; Williams et al., 2015). At $\mathrm{pH} 4.8$, near-complete donor atom protonation minimizes interactions between cerium(IV) and BTP. The hydrolytically active multinuclear Ce(IV) hydroxo species are unhindered and free to promote hydrolysis through a mechanism in which Ce(IV) binds to negatively charged phosphate oxygen atoms in the lipid, activating phosphorous toward attack, while delivering a hydroxide nucleophile to an adjacent phosphodiester bond (Figure 1K) (Komiyama et al., 1999). At pH 7.2, nitrogen deprotonation enables BTP to bind to Ce(IV) and impede its ability to accelerate cleavage. The promising in vitro results pointing to cerium(IV) as a "lysosomal phospholipase mimic" are consistent with a small molecule approach to reversing the pathogenic lysosomal build-up of sphingomyelin that occurs in Niemann-Pick disease type A, a fatal lysosomal storage disease caused by mutations in the human ASM gene (Schuchman and Desnick, 2017).

In a related study, König and co-workers explored the effects of phosphatidylcholine liposomes on the interactions between the activated DNA model compound bis-4-nitrophenyl phosphate (BNPP) and $\mathrm{Fe}(\mathrm{III}), \mathrm{Cu}(\mathrm{II}), \mathrm{Zn}(\mathrm{II}), \mathrm{Al}(\mathrm{III}), \mathrm{La}(\mathrm{III})$, $\mathrm{Ce}(\mathrm{III}), \mathrm{Eu}(\mathrm{III}), \mathrm{Tb}(\mathrm{III})$, and $\mathrm{Yb}(\mathrm{III})\left(25^{\circ} \mathrm{C}\right.$ and $\mathrm{pH} 7.4$, 24 h; Entry 12 in Table S1; Figure S4) (Poznik et al., 2015). While the $d$ - and $p$ - block metal ions were less active, the five $\operatorname{Ln}($ III) metal centers accelerated hydrolysis of the phosphodiester bonds of the external BNPP substrate. When unactivated PC liposomes were added to the reactions, the hydrolytic activity of only the lanthanide ions toward BNPP was markedly increased ( $11-19 \%$ final yield). The lanthanides were then shown to quench the fluorescence of membrane embedded carboxyfluorescein, leading the authors to propose a hydrolytic mechanism in which densely packed $\operatorname{Ln}$ (III) Lewis acid centers assembled at the lipid-water interface of the PC liposomes accelerate phosphodiester hydrolysis in a cooperative fashion. Dissimilar to Williams et al.'s data (Kassai et al., 2011; Williams et al., 2015), metal-assisted cleavage of unactivated bilayer phosphatidylcholine molecules was not reported.

\section{CONCLUDING REMARKS}

In this review, we have summarized and commented on key research studies in which metal ions and complexes were used to hydrolyze ester and phosphate ester lipid bonds. We found that the metal ion centers $\mathrm{Al}(\mathrm{III}), \mathrm{Cu}(\mathrm{II})$, and $\mathrm{Zn}$ (II) cleave neutral, unactivated ester bonds in acylglycerides and fatty acid esters, mainly at elevated temperatures $\left(50-260^{\circ} \mathrm{C}\right)$. In contrast, the lanthanide/rare earth ions $\mathrm{Ce}(\mathrm{III}), \mathrm{Eu}(\mathrm{III})$, $\mathrm{La}(\mathrm{III}), \mathrm{Lu}(\mathrm{III}), \mathrm{Tb}(\mathrm{III}), \mathrm{Tm}(\mathrm{III}), \mathrm{Yb}(\mathrm{III}), \mathrm{Y}(\mathrm{III})$, and $\mathrm{Ce}(\mathrm{IV})$ work well at $25-37^{\circ} \mathrm{C}$ with lipids containing negatively charged phosphate ester bonds. These mild temperature conditions enable phospholipids in fully assembled liposomes to be cleaved. Among the lanthanides, Ln(III) ions were primarily used to hydrolyze $p$-nitrophenol activated phosphate ester lipid bonds in neutral to mildly alkaline $\mathrm{pH}$ environments $(\mathrm{pH} 7.0-8.5)$. In the case of phosphatidylinositol, the 2-hydroxyl group of inositol serves as an internal nucleophile, permitting Ln(III)assisted hydrolysis of liposomes to proceed in the absence of a phosphate ester activating group. The lanthanide ion $\mathrm{Ce}(\mathrm{IV})$ favors mildly acidic conditions over near neutral $\mathrm{pH}$, 
and at $37^{\circ} \mathrm{C}$ is highly reactive toward the hydrolytic cleavage of unactivated phosphatidylcholine phosphate ester bonds. In addition to relating the mechanistic aspects of lipid hydrolysis, the research articles showcased in this review underscore the potential of metal ions and complexes to serve as hydrolytic agents in diverse applications ranging from biofuel production to therapeutics.

\section{AUTHOR CONTRIBUTIONS}

All authors listed have made a substantial, direct and intellectual contribution to the work, and approved it for publication.

\section{REFERENCES}

Almora-Barrios, N., Pogodin, S., Bellarosa, L., Garcia-Melchor, M., RevillaLopez, G., Garcia-Rates, M., et al. (2015). Structure, activity, and deactivation mechanisms in double metal cyanide catalysts for the production of polyols. Chem. Cat. Chem. 7, 928-935. doi: 10.1002/cctc.201402907

Appelqvist, H., Wäster, P., Kågedal, K., Öllinger, K. (2013). The lysosome: from waste bag to potential therapeutic target. J. Mol. Cell Biol. 5, 214-226. doi: $10.1093 / \mathrm{jmcb} / \mathrm{mjt} 022$

Boyer, R. F., Wernette, M. E., Van Wylen, S., Faustman, E., and Titus, R. (1979). 2-Hydroxy acids as biochemical ligands. Copper(II)-facilitated hydrolysis of 2-hydroxy acid esters. J. Inorg. Biochem. 10, 205-213. doi: 10.1016/S0162-0134(00)80280-9

Bracken, K., Moss, R. A., and Ragunathan, K. G. (1997). Remarkably rapid cleavage of a model phosphodiester by complexed ceric ions in aqueous micellar solutions. J. Am. Chem. Soc. 119, 9323-9324. doi: 10.1021/ja971448b

Burgess, J. (1978). Metal Ions in Solution. New York, NY: Halstead Press.

Cepeda, S. S., Williams, D. E., and Grant, K. B. (2012). Evaluating metal ion salts as acid hydrolase mimics: metal-assisted hydrolysis of phospholipids at lysosomal pH. Biometals 25, 1207-1219. doi: 10.1007/s10534-012-9583-1

Cocco, L., Follo, M. Y., Manzoli, L., and Suh, P. G. (2015). Phosphoinositidespecific phospholipase C in health and disease. J. Lipid Res. 56, 1853-1860. doi: 10.1194/jlr.R057984

Coumans, A. E., and Hensen, E. J. M. (2017). A model compound (methyl oleate, oleic acid, triolein) study of triglycerides hydrodeoxygenation over alumina-supported NiMo sulfide. Appl. Catal. B. Environ. 201, 290-301. doi: 10.1016/j.apcatb.2016.08.036

Franklin, S. J. (2001). Lanthanide-mediated DNA hydrolysis. Curr. Opin. Chem. Biol. 5, 201-208. doi: 10.1016/S1367-5931(00)00191-5

Grant, K. B., and Kassai, M. (2006). Major advances in the hydrolysis of peptides and proteins by metal ions and complexes. Curr. Org. Chem. 10, 1035-1049. doi: 10.2174/138527206777435535

Hajjari, M., Tabatabaei, M., Aghbashlo, M., and Ghanavati, H. (2017). A review on the prospects of sustainable biodiesel production: A global scenario with an emphasis on waste-oil biodiesel utilization. Renew. Sust. Energ. Rev. 72, 445-464. doi: 10.1016/j.rser.2017.01.034

Hama, H. (2010). Fatty acid 2-hydroxylation in mammalian sphingolipid biology. Biochim. Biophys. Acta. 1801, 405-414. doi: 10.1016/j.bbalip.2009.12.004

Hauser, H., and Phillips, M. C. (1976). Conformation of the lecithin polar group in charged vesicles. Nature 261, 390-394. doi: 10.1038/261390a0

Jenkins, R. W., Canals, D., and Hannun, Y. A. (2009). Roles and regulation of secretory and lysosomal acid sphingomyelinase. Cell Signal. 21, 836-846. doi: 10.1016/j.cellsig.2009.01.026

Kassai, M., Teopipithaporn, R., and Grant, K. B. (2011). Hydrolysis of phosphatidylcholine by cerium(IV) releases significant amounts of choline and inorganic phosphate at lysosomal pH. J. Inorg. Biochem. 105, 215-223. doi: 10.1016/j.jinorgbio.2010.11.007

Kishimoto, Y., and Radin, N. S. (1963). Occurrence of 2-hydroxy fatty acids in animal tissues. J. Lipid Res. 4, 139-143.

Knothe, G. (2010). Biodiesel and renewable diesel: a comparison. Prog. Energy Combust. Sci. 36, 364-373. doi: 10.1016/j.pecs.2009.11.004

\section{FUNDING}

Our phospholipid research program received financial support from the Georgia State University Molecular Basis of Disease Program (DW) and the National Science Foundation (CHE-0718634, KG).

\section{SUPPLEMENTARY MATERIAL}

The Supplementary Material for this article can be found online at: https://www.frontiersin.org/articles/10.3389/fchem. 2019.00014/full\#supplementary-material

Komiyama, M., Takeda, N., and Shigekawa, H. (1999). Hydrolysis of DNA and RNA by lanthanide ions: mechanistic studies leading to new applications. Chem. Commun. 1443-1451. doi: 10.1039/a901621j

Li, Z., Jiang, H., Xie, W., Zhang, Z., Smrcka, A. V., and Wu, D. (2000). Roles of PLC-beta2 and -beta3 and PI3Kgamma in chemoattractant-mediated signal transduction. Science 287, 1046-1049. doi: 10.1126/science.287.5455.1046

Liu, H. X., Hu, J., Liu, X. T., Li, R. C., and Wang, K. (2001). Effects of lanthanide ions on hydrolysis of phosphatidylinositol in human erythrocyte membranes. Chinese Sci. Bull. 46, 401-403. doi: 10.1007/BF03183274

Maldonado, A. L., and Yatsimirsky, A. K. (2005). Kinetics of phosphodiester cleavage by differently generated cerium(IV) hydroxo species in neutral solutions. Org. Biomol. Chem. 3, 2859-2867. doi: 10.1039/b506170a

Mancin, F., Prins, L. J., Pengo, P., Pasquato, L., Tecilla, P., and Scrimin, P. (2016). Hydrolytic metallo-nanozymes: From micelles and vesicles to gold nanoparticles. Molecules 21:1014. doi: 10.3390/molecules21081014

Mancin, F., Scrimin, P., and Tecilla, P. (2012). Progress in artificial metallonucleases. Chem. Commun. 48, 5545-5559. doi: 10.1039/c2cc30952a

Matsumura, K., and Komiyama, M. (1994). Hydrolysis of phosphatidylinositol by rare-earth-metal ion as a phospholipase-C mimic. J. Inorg. Biochem. 55, 153-156. doi: 10.1016/0162-0134(94)85037-2

Matsuzawa, Y., and Hostetler, K. Y. (1980). Properties of phospholipase C isolated from rat liver lysosomes. J. Biol. Chem. 255, 646-652.

Moss, R. A., Park, B. D., Scrimin, P., and Ghirlanda, G. (1995). Lanthanide cleavage of phosphodiester liposomes. Chem. Commun. 1627-1628. doi: 10.1039/c39950001627

Ong, L. K., Nguyen, P. L. T., Soetaredjo, F. E., Ismadji, S., and Ju, Y. H. (2016). Direct reuse of Cu-laden wastewater for non-edible oil hydrolysis: basic mechanism of metal extraction and fatty acid production. RSC Adv. 6, 25359-25367. doi: 10.1039/C5RA23153A

Ong, L. K., Nguyen, P. L. T., Soetaredjo, F. E., Ismadji, S., and Ju, Y. H. (2017). Kinetic evaluation of simultaneous waste cooking oil hydrolysis and reactive liquid-liquid $\mathrm{Cu}$ extraction from synthetic $\mathrm{Cu}$-containing wastewater: effect of various co-contaminants. Sep. Purif. Technol. 187, 184-192. doi: 10.1016/j.seppur.2017.06.049

Poznik, M., Maitra, U., and König, B. (2015). The interface makes a difference: lanthanide ion coated vesicles hydrolyze phosphodiesters. Org. Biomol. Chem. 13, 9789-9792. doi: 10.1039/C5OB01265A

Satyarthi, J. K., Srinivas, D., and Ratnasamy, P. (2011). Hydrolysis of vegetable oils and fats to fatty acids over solid acid catalysts. Appl. Catal. A. Gen. 391, 427-435. doi: 10.1016/j.apcata.2010.03.047

Schuchman, E. H., and Desnick, R. J. (2017). Types A and B Niemann-Pick disease. Mol. Genet. Metab. 120, 27-33. doi: 10.1016/j.ymgme.2016.12.008

Scrimin, P., Caruso, S., Paggiarin, N., and Tecilla, P. (2000). Ln(III)catalyzed cleavage of phosphate-functionalized synthetic lipids: real time monitoring of vesicle decapsulation. Langmuir 16, 203-209. doi: 10.1021/ la990804w

Scrimin, P., Tecilla, P., Moss, R. A., and Bracken, K. (1998). Control of permeation of lanthanide ions across phosphate-functionalized liposomal membranes. J. Am. Chem. Soc. 120, 1179-1185. doi: 10.1021/ja972041+

Wenk, M. R. (2010). Lipidomics: new tools and applications. Cell 143, 888-895. doi: $10.1016 /$ j.cell.2010.11.033 
Wezynfeld, N. E., Fraczyk, T., and Bal, W. (2016). Metal assisted peptide bond hydrolysis: chemistry, biotechnology and toxicological implications. Coord. Chem. Rev. 327, 166-187. doi: 10.1016/j.ccr.2016. 02.009

Williams, D. E., Basnet, K., and Grant, K. B. (2015). Tuning cerium(IV)assisted hydrolysis of phosphatidylcholine liposomes under mildly acidic and neutral conditions. ChemBioChem 16, 1474-1482. doi: 10.1002/cbic. 201500041

Wischert, R., Florian, P., Coperet, C., Massiot, D., and Sautet, P. (2014). Visibility of $\mathrm{Al}$ surface sites of gamma-alumina: a combined computational and experimental point of view. J. Phys. Chem. C 118, 15292-15299. doi: $10.1021 /$ jp $503277 \mathrm{~m}$

Wulfsberg, G. (1987). Principles of Descriptive Inorganic Chemistry. Monterey, CA: Brooks/Cole Publishing Company.
Yu, L., Li, F. Z., Wu, J. Y., Xie, J. Q., and Li, S. (2016). Development of the azacrown ether metal complexes as artificial hydrolase. J. Inorg. Biochem. 154, 89-102. doi: 10.1016/j.jinorgbio.2015.09.011

Conflict of Interest Statement: The authors declare that the research was conducted in the absence of any commercial or financial relationships that could be construed as a potential conflict of interest.

Copyright $\odot 2019$ Williams and Grant. This is an open-access article distributed under the terms of the Creative Commons Attribution License (CC BY). The use, distribution or reproduction in other forums is permitted, provided the original author(s) and the copyright owner(s) are credited and that the original publication in this journal is cited, in accordance with accepted academic practice. No use distribution or reproduction is permitted which does not comply with these terms. 